\title{
Evidence- based medicine among family physicians in Mosul city: knowledge and attitudes
}

\author{
Anmar B. Al-Dewachi \\ From the Department of Community Medicine, College of Medicine, University of Mosul. \\ Correspondence: Anmar B. Al-Dewachi. Lecturer, Department of Community Medicine, College of Medicine, University of \\ Mosul, Mosul, Iraq. Email: anmaraldewachi@yahoo.com. \\ (Ann Coll Med Mosul 2013; 39 (1): 38-44) \\ Received: $2^{\text {nd }}$ Nov. 2012; Accepted: $27^{\text {th }}$ Apr. 2013.
}

\section{ABSTRACT}

Objectives: The aim of this study is to assess knowledge and attitudes of family physicians in Mosul city toward evidence-based medicine and to describe the major barriers to practicing evidence based medicine.

Method: A cross sectional questionnaire based survey has been adopted for this study. For the period between the $1^{\text {st }}$ of June and $31^{\text {st }}$ of August 2012; a self-administered questionnaire had been distributed to all 71 family physicians registered in Nineveh Health Directorate and practicing in primary health centers in Mosul city. The main outcome measures were: participants' attitudes toward evidence -based medicine (EBM), their knowledge about the important technical terms used in EBM and their perception of barriers to EBM practice.

Results: Sixty one family physicians participated in this study, 24 (39.3\%) were males and 37 (60.7\%) were females. The response rate was $85.9 \%$. The mean age of the participants was 36.15 years. Most of the respondents had positive attitudes toward EBM: $54.1 \%$ showed welcoming attitudes towards EBM; $44.3 \%$ showed strongly welcoming attitudes towards EBM; $65.6 \%$ believed that most of their clinical practice was evidence based; $90 \%$ agreed with the concept of practicing EBM improves patients care. The participants showed deficient knowledge regarding the technical terms commonly used in EBM. Patients overload and lack of personal time were the major perceived barriers to practicing EBM (78.7\% and $65.6 \%)$ respectively. Conclusion: Although this research revealed high support among family physicians in Mosul for the practice of EBM, they showed a deficiency in knowledge about EBM.

Keywords: EBM, family physicians, family medicine, knowledge, attitudes.

\section{الطب المبني على الاليل بين أطباء الأسرة في مدينة الموصل: المعارف والمواقف}

الخلاصة أهداف الاراسة: تقييم معارف ومواقف أطباء الأسرة في مدينة الموصل من الطب المبني على الدليل، وكذلك لوصف المعوقات

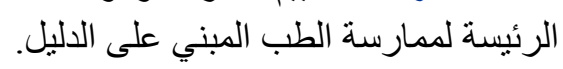

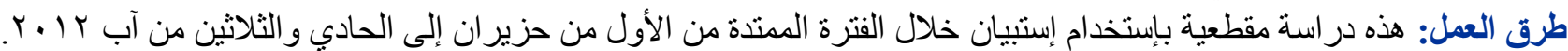

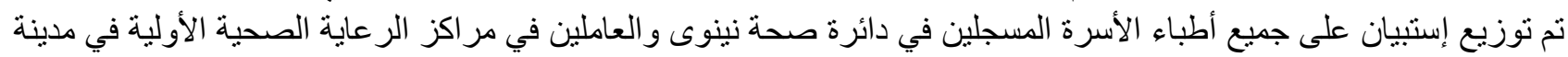

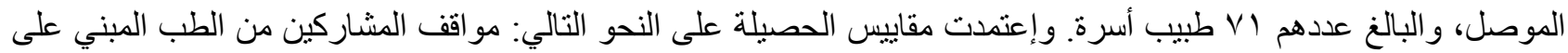

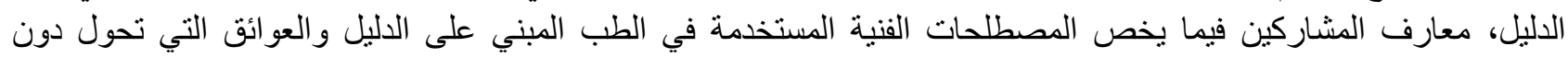
ممارستهم للطب المبني على الدليل.

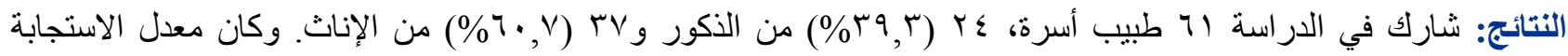

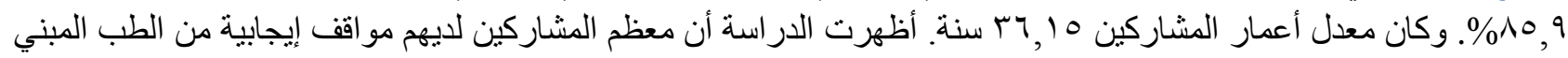

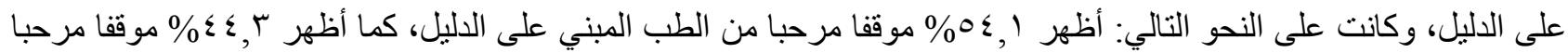

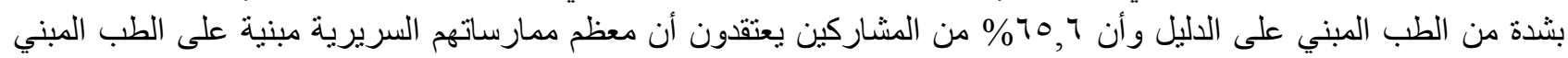


على الدليل و أن • 9\% من المشاركين متفقون مع المفهوم القائل أن الطب المبني على الدليل يحسن مستوى الرعاية الصحية المقدمة

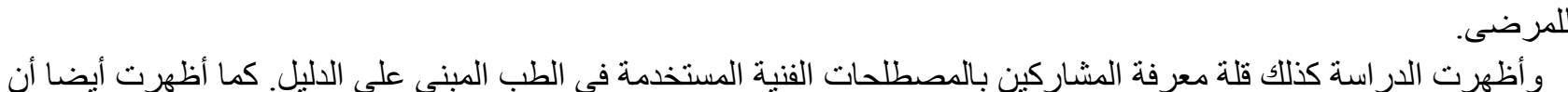

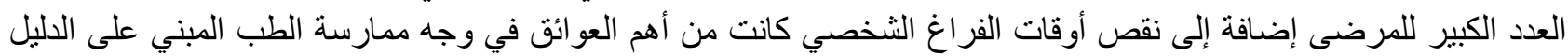

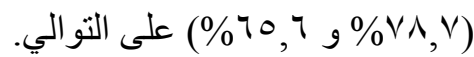
الاستنتاج: على الرغم من أن هذا البحث أظهر تأييدا عاليا من قبل أطباء الأسرة في مدينة الموصل لممارسة الطب المبني على الميل

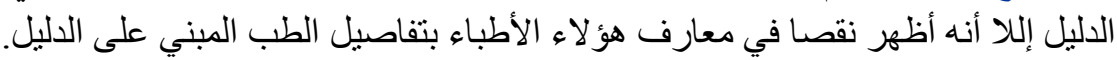

E vidence-based medicine (EBM) remains a hot topic among health care providers and any observer can see that physician's attitude towards utilizing EBM in their practice vary widely ${ }^{(1)}$.

Evidence-based medicine is defined as the conscientious, explicit, and judicious use of current best evidence in making decisions about the care of individual patients ${ }^{(1)}$. It was developed in the early 1990s to improve medical decision-making and the term and concept originated at Mc-Master University in Canada ${ }^{(2)}$.

Evidence-based medicine has emerged as a new paradigm for medical practice, integrating individual clinical expertise with the best available external clinical evidence and compassionate use of individual patients' rights and preferences in making clinical decisions about their care $^{(3)}$. Providing evidence-based care to patients involves turning a clinical problem into an answerable question, systematically searching for the best evidence relevant to the question, critically appraising that evidence, and using the evidence as the basis for clinical decisions to solve the problem ${ }^{(4)}$

Family physicians are patients' first point of contact with health services. They provide ongoing comprehensive care and are fundamental to the coordination of care across the health care system. Within this broad and complex work activities, family practitioners make thousands of clinical decisions each year about patients diagnosis, treatment and prognosis; however, it is difficult to ascertain how many of these decisions are consistent with the best available evidence. ${ }^{(5)}$

The need to apply EBM and to develop EBM guidelines and performance indicators for the management of commonly encountered problems in general practice and primary care has been detailed in several papers ${ }^{(5-11)}$.

A pioneer study was conducted in United Kingdom (UK) in 1998 to determine the attitudes of
UK general practitioners towards EBM, most of them had welcoming attitudes toward EBM and agreed that it improves patient care. However there was a low level of awareness about extracting journals, review publications and databases relevant to EBM, and the major perceived barrier to its practice was lack of personal time ${ }^{(12)}$. Many other studies conducted among primary health care and family physicians showed similar findings ${ }^{(13-18)}$.

Based on the above background, the aim of this study is to assess knowledge and attitudes of family physicians in Mosul city toward EBM and to describe the major barriers to practicing this theme.

\section{SUBJECTS AND METHODS}

A cross sectional questionnaire based survey has been adopted for this study.

For the period between the $1^{\text {st }}$ of June and $31^{\text {st }}$ of August 2012, a self-administered questionnaire had been distributed to all 71 family physicians registered in Nineveh Health Directorate and practicing in primary health centers in Mosul city.

All family medicine specialists and residents (diploma and board residents) were included in this study. General practitioners who are not enrolled in family medicine residency program (diploma or board residency programs) were excluded from this study.

The data collection tool was a questionnaire adopted from Mc Coll et al ${ }^{(12)}$, which was carried out to determine attitude of UK general practionnairs toward EBM and was modified according to the present study locality.

The questionnaire has four sections. The first section asks the respondents to describe their professional and personal characteristics (age, sex, qualifications, no. of years of working in primary health care and no. of patients seen daily). 
The second section related to the respondents attitudes towards EBM (welcoming current promotion of EBM, colleagues attitudes towards EBM, whether EBM is useful in their daily management and whether EBM improves patient care).

The third section test participants knowledge regarding certain technical terms commonly used in evidence based medicine (sensitivity, specificity, systematic review, meta-analysis, odds ratio and relative risk) by using a multiple choice questions.

The last section includes information about barriers to EBM faced by the physicians in obtaining and searching for data (patients overload, lack of personal time, lack of investment by health authorities, no financial gain in using EBM, lack of hard evidence, too much evidence, evidence is not related to context of primary health care, patient expectation, lack of critical appraisal skills and others).

Statistical analysis of data was performed addressing the following main outcome measures: participants' attitudes toward EBM, their knowledge about the important technical terms used in EBM and their perception of barriers to EBM practice.

The collected data analyzed using SPSS version 14. Tables of frequencies and proportions were used to evaluate the variables.

\section{RESULTS}

Completed questionnaires were received from 61 family physicians. The response rate was $85.9 \%$. The non-respondents dropped in one of two categories: those with incomplete questionnaires, and those who did not return back the forms. The mean age of the participants was 36.15 years. More than half $(50.8 \%)$ were in age category $36-45$ years. Of the respondents, 24 (39.3\%) were males and 37 (60.7\%) were females; 19.7\% were specialists and the remaining were residents; $42.6 \%$ of them had practicing in primary health care $1-5$ years and $42.6 \%$ examined $30-45$ patients daily (Table 1).

Table 2 shows the attitudes of family physicians toward EBM; $54.1 \%$ of the participants showed welcoming attitudes; $44.3 \%$ showed strongly welcoming attitudes towards current promotion of EBM and $73.7 \%$ described a welcoming attitudes of their colleagues towards EBM.
Almost two thirds $(70.5 \%)$ of participants agreed that research findings are useful in daily practice and $19.7 \%$ found it extremely useful. However, only $65.6 \%$ believed that most of their clinical practice was evident based.

Ninety five percent of the participants agreed with the concept of practicing EBM improve patients care and $62.3 \%$ of them do not agree with the notion that "EBM is of limited value in family medicine".

Table 3 reveals knowledge assessment of participants about some technical terms used in EBM. The proportions of correct answer regarding common terms used in EBM (sensitivity, specificity, odds ratio and relative risk) were $39.3 \%, 37.7 \%$, $45.9 \%$ and $42.6 \%$ respectively. On the other hand, the terms systematic review and meta-analysis have a fraction of correct answers of $26.3 \%$ and $29.5 \%$ respectively.

Table 4 shows the perceived barriers by the respondents to practicing EBM. Patients overload was the major perceived barrier identified in $78.7 \%$ of participants, followed by lack of personal time which identified in $65.6 \%$ of participants. Both patient expectations and lack of investment by health authorities were the third most commonly identified barrier (41.0\%).

Table 1. General characteristics of study participants

\begin{tabular}{|l|c|c|}
\hline \multicolumn{1}{|c|}{ Variable } & No. & $\%$ \\
\hline Age & & \\
\hline $25-35$ & 23 & 37.7 \\
\hline $36-45$ & 31 & 50.8 \\
\hline$>45$ & 7 & 11.5 \\
\hline Sex & & \\
\hline Male & 24 & 39.3 \\
\hline Female & 37 & 60.7 \\
\hline Qualification & & \\
\hline Specialist & 12 & 19.7 \\
\hline FM board resident & 37 & 60.6 \\
\hline FM diploma resident & 12 & 19.7 \\
\hline No. of years of working in PHC & & \\
\hline$<1$ & 10 & 16.4 \\
\hline $1-5$ & 26 & 42.6 \\
\hline $6-10$ & 14 & 23.0 \\
\hline $11-15$ & 8 & 13.1 \\
\hline $16-20$ & 3 & 4.9 \\
\hline$>20$ & 0 & 0.0 \\
\hline No. of patients seen daily & & \\
\hline$<30$ & 21 & 34.4 \\
\hline $31-45$ & 26 & 42.6 \\
\hline $46-70$ & 8 & 13.1 \\
\hline$>70$ & 6 & 9.9 \\
\hline & & \\
\hline & & \\
\hline & & \\
\hline
\end{tabular}


Table 2. Family physicians attitudes toward EBM.

\begin{tabular}{|c|c|c|}
\hline Attitude & No. & $\%$ \\
\hline \multicolumn{3}{|l|}{$\begin{array}{l}\text { 1. Attitude toward current } \\
\text { promotion of EBM }\end{array}$} \\
\hline Strongly welcoming & 27 & 44.3 \\
\hline Welcoming & 33 & 54.1 \\
\hline Not welcoming & 1 & 1.6 \\
\hline Don't know & 0 & 0.0 \\
\hline \multicolumn{3}{|l|}{ 2. Colleagues attitude toward EBM } \\
\hline Strongly welcoming & 7 & 11.5 \\
\hline Welcoming & 45 & 73.7 \\
\hline Not welcoming & 2 & 3.3 \\
\hline Don't know & 7 & 11.5 \\
\hline \multicolumn{3}{|l|}{$\begin{array}{l}\text { 3. Usefulness of research finding in } \\
\text { daily practice }\end{array}$} \\
\hline Extremely useful & 12 & 19.7 \\
\hline Useful & 43 & 70.5 \\
\hline Not useful & 3 & 4.9 \\
\hline Don't know & 3 & 4.9 \\
\hline \multicolumn{3}{|l|}{$\begin{array}{l}\text { 4. Percentage of physician's } \\
\text { clinical practice that is evidence } \\
\text { based }\end{array}$} \\
\hline $75-100 \%$ & 8 & 13.1 \\
\hline $50-74 \%$ & 32 & 52.5 \\
\hline $25-49 \%$ & 16 & 26.2 \\
\hline $0-24 \%$ & 5 & 8.2 \\
\hline \multicolumn{3}{|l|}{$\begin{array}{l}\text { 5. Practicing EBM improve patient } \\
\text { care }\end{array}$} \\
\hline Strongly agree & 29 & 47.5 \\
\hline Agree & 29 & 47.5 \\
\hline Not agree & 1 & 1.6 \\
\hline Don't know & 2 & 3.3 \\
\hline \multicolumn{3}{|l|}{$\begin{array}{l}\text { 6. EBM of limited value in family } \\
\text { medicine. }\end{array}$} \\
\hline Strongly agree & 4 & 6.56 \\
\hline Agree & 7 & 11.47 \\
\hline Not agree & 38 & 62.30 \\
\hline Don't know & 12 & 19.67 \\
\hline
\end{tabular}

Table 3. Assessment of knowledge of family physicians about some technical terms commonly used in EBM.

\begin{tabular}{|l|c|c|}
\hline \multicolumn{1}{|c|}{ Terms } & $\begin{array}{c}\text { Correct } \\
\text { answer } \\
\text { No. (\%) }\end{array}$ & $\begin{array}{c}\text { Incorrect } \\
\text { answer } \\
\text { No. (\%) }\end{array}$ \\
\hline Sensitivity & $24(39.3)$ & $37(60.7)$ \\
\hline Specificity & $23(37.7)$ & $38(62.3)$ \\
\hline Systematic review & $16(26.3)$ & $45(73.7)$ \\
\hline Meta-analysis & $18(29.5)$ & $43(70.5)$ \\
\hline Odds ratio & $28(45.9)$ & $33(54.1)$ \\
\hline Relative risk & $26(42.6)$ & $35(57.4)$ \\
\hline
\end{tabular}

Table 4. Factors perceived by the respondents as a barriers to practicing EBM.

\begin{tabular}{|l|c|}
\hline \multicolumn{1}{|c|}{ Barrier } & No. (\%) \\
\hline Patient overload & $48(78.7)$ \\
\hline Lack of personal time & $40(65.6)$ \\
\hline Lack of investment by health authorities & $25(41.0)$ \\
\hline No financial gain in using EBM & $10(16.4)$ \\
\hline Lack of hard evidence & $11(18.0)$ \\
\hline $\begin{array}{l}\text { Evidence is not related to context of } \\
\text { primary health care }\end{array}$ & $22(36.1)$ \\
\hline Too much evidence & $21(34.4)$ \\
\hline Patient expectation & $25(41.0)$ \\
\hline Lack of critical appraisal skills & $16(26.2)$ \\
\hline others & $4(6.6)$ \\
\hline
\end{tabular}

\section{DISCUSSION}

EBM is a growing worldwide movement in health care that aims to bring the best evidence from medical research to the bedside, clinic and community. It is strongly believed that if the concept of delivering an evidence based practice is embraced, it will improve primary health care in a number of different ways. First, it will support shared decision making with users, which is advocated increasingly as the ideal model for making decision within the medical encounter. ${ }^{(19,20)}$ Secondly, it will help to maintain the central role of family medicine in health care ${ }^{(21)}$.

The overall response rate in this study was $85.9 \%$ which is regarded as a good response rate to a questionnaire survey when it is compared with other studies ${ }^{(22-26)}$. A similar results was found in a study done in Saudi Arabia in 2006 to assess the attitudes, awareness and practice of consultant physicians towards EBM and the response rate was $85.5 \%{ }^{(16)}$. This high response rate may be due to the fact that most of the participants were keen to participate in this study and enthusiastic to bring EBM to the daily practice, in addition to the proper way of distribution and collection of the questionnaires. 
In this research, the vast majority of the respondents (98.4\%) had a conclusively positive attitude towards EBM, which is consistent with the results from other medical researches. $(12-14,16,18,27)$ This is a good sign for encouragement of the use of EBM in primary health care settings to improve patients' management.

Despite that $95 \%$ of the participants agreed with the concept of practicing EBM improve patients care; only $65.6 \%$ believed that most of their clinical practice was evidence based. This is a higher than the figure of $50 \%$ reported by McColl et al ${ }^{(12)}$, but it is consistent with the results of similar study done in Saudi Arabia ${ }^{(13)}$. Although the validity of this subjective assessment is untested, objective measures of the proportion of general practice that is evidence-based are also fraught with difficulties due to unclear definitions of diagnosis, interventions, and levels of evidence and availability and use of valid audit tools. ${ }^{(28)}$ Family medicine, which centers on the individual patientdoctor relationship and the interaction between biomedical, personal, and contextual perspectives, might require different research strategies and allowance for more circumstantial evidence rather than the watertight evidence accrued by randomized controlled trials. ${ }^{(29)}$

More than $60 \%$ of the respondents disagreed with the notion that "EBM is of limited value in primary health care" these findings are consistent with the results of another research done in Jordan in 2009. (18)

The questionnaire used in this study was adopted from Mc Coll et al ${ }^{(12)}$ which was carried out to determine attitude of UK general practionnairs toward EBM, with some modifications. Using previously published questionnaire thought to add strength to the study because its validity has been already tested and would allow international comparison to be done.

Many of the previously published similar medical literatures which assessed the knowledge of family physicians about some technical terms used in EBM had some methodological shortcomings, as their questionnaire relied on doctors self-rated assessment of their own knowledge. ${ }^{(12,14,16-18)}$ Research participants may be unwilling to disclose their knowledge deficiencies. This might shed doubt on the objectivity of the responses, introducing potential biases. In the present study this defect was overcome by using an objective way of assessment of the participant's knowledge about these technical terms through a multiple choice questions rather self-rated assessment.

In the present study the respondents showed a fractional understanding of the technical terms used in EBM. This finding is consistent with that from other medical literatures. ${ }^{(12,13,18)}$ Interpretation of evidence is a key element in practicing evidence based medicine, and this fractional understanding could deter interpretation and make cascading of evidence to other members of the primary care team more difficult.

The major perceived barriers to practicing EBM was patients overload (78.7\%) and lack of personal time (65.6\%). Patients overload would be possibly translated into lack of personal time. The picture of the overworked physicians with little time is a consistent one within the medical literatures $(12,13,17,18,22)$. One way to increase the time available for EBM through changing the emphasis of postgraduate-study from lectures to training in accessing and interpreting evidence and then spending time putting these skills into practice. ${ }^{(6)}$ Dawes in 2006 suggested that a general practitioner who spends an hour a week searching and reading would make huge strides in implementing evidence. ${ }^{(6)}$

Lack of investment by the health authorities was identified as a barrier to practicing EBM in 41.0\%; this might arise from the concept that investment and training in the field of EBM might add a more financial burden on health authorities which is enormous misinterpretation of its financial consequences. Physicians who practice EBM will identify and apply the most efficacious interventions to maximize the quality and quantity of life for individual patients; this would lower rather than raise the cost of their care. ${ }^{(1,30)}$

Family medicine is a new discipline in Iraq; implementing a change and introducing new concepts to the discipline is still feasible. The results of this research should be taken in consideration by post-graduate tutors, Ministry of Health, local health authorities and University Department of Family and Community Medicine in designing local strategies for encouraging the implementation of EBM in primary health care. 


\section{CONCLUSION}

Although this research revealed high support among family physicians in Mosul for the practice of EBM, they showed a deficiency in knowledge about EBM. Hence, the time appears ripe for planning and implementing an effective EBM educational program for both undergraduate medical students and postgraduate doctors.

\section{RECOMMENDATIONS}

The research recommends upgrading the knowledge of family physicians about EBM to provide good media for learning and practicing EBM in primary health care settings. This can be achieved by incorporating an effective EBM teaching program in family medicine postgraduate- studies and organizing further courses to improve knowledge of primary health care physicians about research methodology, critical appraisal and other skills of EBM. In addition, the research recommends further studies to assess knowledge of all hospital doctors about EBM.

Acknowledgments: The author would like to thank Pr. Asma Al-jawadi and Dr. Dhafer B. Alyouzbaki for their advice and support. I would like also to thank all the respondents, family medicine specialists and residents in Mosul, who spared their valuable time to answer the questionnaires.

\section{REFERENCES}

1. Sackett DL, Rosenberg WM, Gray JA, Haynes RB, Richardson WS. Evidence based medicine: what it is and what it isn't. BMJ 1996;312:71-72.

2. Evidence-Based Medicine Working Group. Evidence based medicine. A new approach to teaching the practice of medicine. JAMA 1992;268:2420-2425.

3. Mears R, Sweeney K. A preliminary study of the decision-making process within general practice. Fam Pract. 2000;17:428-9.

4. Tanjong-Ghogomu E, Tugwell $P$, Welch V. Evidencebased medicine and the Cochrane Collaboration. Bull NYU Hosp Jt Dis.2009;67:198-205.

5. Ridsdale L. Evidence-based learning for general practice. British Journal of General Practice 1996; 46:503-504.

6. Dawes M. On the need for evidence-based general and family practice. Evidence-based Medicine 1996; $1: 68-69$.

7. Baker R. North of England evidence based guidelines development project: Summary version of evidence based guideline for the primary care management of stable angina. British Medical Journal 1996;312:827832

8. North of England Asthma Guideline Development Group. North of England evidence based guidelines development project: summary version of evidence based guideline for the primary care management of asthma in adults. British Medical Journal 1996; 312:762766.

9. Eccles M. North of England evidence based guidelines development project: methods of guideline development. British Medical Journal 1996; 312:760762.

10. McColl A. Performance indicators for primary care groups: an evidence based approach. British Medical Journal 1998;317:1354-1360.

11. Gill P. Evidence based general practice: a retrospective study of interventions in one training practice. British Medical Journal 1996;312:819-821.

12. McColl A, Smith $H$, White $P$, Field J. General practitioners' perceptions of the route to evidence based medicine: a questionnaire survey. British Medical Journal 1998;316:361-365.

13. Al-Ansary LA, Khoja TA. The place of evidencebased medicine among primary health care physicians in Riyadh region, Saudi Arabia. Fam Pract 2002;19(5):53742

14. Al-Baghlie N, Al-Almaie SM. Physician attitudes towards evidence-based medicine in eastern Saudi Arabia. Ann Saudi Med 2004;24(6):425-8.

15. Al-Almaie SM, AL-Baghli N. Barriers facing physicians practicing evidence based medicine in Saudi Arabia. J Contin Educ Health Prof 2004;24(3):163-70.

16. Al-Omari FK, Al-Asmary SM. Attitude, awareness and practice of evidence based medicine among consultant physicians in Western region of Saudi Arabia. Saudi Med J 2006;27(12):1887-93.

17. Amin FA, Fedorowicz Z, Montgomery AJ. A study of knowledge and attitudes toward the use of evidencebased medicine among primary health care physicians in Bahrain. Saudi Med J 2006;27(9):1394-6.

18. Barghouti F, Halaseh L, Said T, et al. Evidence based medicine among Jordanian Family physicians: Awareness, attitude and knowledge. Can Fam physician 2009;55:e6-13.

19. Dowie J. 'Evidence-based',' cost -effective 'and 'performance driven' medicine: decision analysis based medical decision making is the pre-requisite. $J$ health Serv Res policy 1996;1:104-113.

20. Silagy C, Haines A. Evidence Based Practice in Primary Care. $1^{\text {st }}$ edition. London: BMJ Publishing Group,1998. p. 1-10.

21. Baker M, Maskney NM, Kirks S. Clinical Effectiveness and Primary Care. $1^{\text {st }}$ edition. Abingdon: Radcliffe Medical Press,1997. p.78.

22. Scott I, Heyworth R, Fairweather P. The use of evidence-based medicine in practice of consultant physicians. Results of questionnaire survey. Aust NZJ Med 2000; 30: 319-326.

23. Mc Alister FA, Graham I, Kar GW, Laupacies A. Evidence -Based Medicine and practicing clinician. Journal of General Internal Medicine 1999;14: 236.

24. Veness M, Rikard-Bell G, Ward J. Views of Austraalian \& New Zealand radiation oncologists \& registrars about evidence based medicine and their access to internet based source of evidence. Australas Radiol $2003 ; 47: 409-415$.

25. Kerridge I, Lowe M, Henry D. Ethics and evidence based medicine. BMJ 1998;316:1151-1153. 
26. Moawad MA. Physcian attitudes toward evidence based medicine: Is their room for improvement ? Ann Saudi Med 2004;24:423-424.

27. Al-Kubaisi NJ, Al-Dahnaim LA, Salama RE. Knowledge, attitude and practices of primary health care physicians towards evidence-based medicine in Doha, Qatar. EMHJ 2010;16 (11): :1189-1196.

28. Young JM, Ward JE. Evidence-based medicine in general practice: beliefs and barriers among Australian GPs. J Eval Clin Pract 2001;7(2):201-10.
29. Jacobson LD, Edwards AG, Granier SK, Butler CC. Evidence-based medicine and general practice. $\mathrm{Br} J$ Gen Pract 1997;47(420):449-52.

30. Tracy CS, Dantas GS, Upshur RE. Evidence-based medicine in primary care: qualitative study of family physicians. BMC Fam Pract 2003;4:6. 